\title{
Editorial: Prizes awarded by the European Ecological Federation
}

\author{
S. Klotz \\ Helmholtz-Ctr. Environmental Research, Theodor-Lieser-Str. 4, 06120 Halle/Saale, Germany \\ Correspondence to: S. Klotz (stefan.klotz@ufz.de)
}

The European Ecological Federation (EEF; http://www. europeanecology.org/) is made up of ecological societies from European countries. Presently, the EEF includes 17 member societies representing more than 8000 ecologists from more than 20 European countries. The European Ecological Federation enables cooperation between European ecological societies in order to promote the science of ecology in Europe. It does this through providing a forum for effective communication throughout the community of ecological scientists in Europe on matters of common interest. It is disseminating ecological knowledge through meetings, publications (e.g. with the Open Access journal Web Ecology) and other means and is acting as an advisory, consultative and representative capacity in relation to European institutions. The main goal of the EEF is to promote collaborative activity on those matters where there is a pan-European context and cooperating with other international organisations.

Since 2011 the EEF endows two prizes to be awarded during the biennial EEF congress to both a senior scientist and a young academic for outstanding scientific activities.

\section{The Ernst Haeckel Prize}

The Ernst Haeckel Prize was awarded for the first time in 2011 (awardee: Georgina Mace, University College London). It is designed to honour a senior ecologist for an outstanding contribution to European ecological science.

The award is named after Ernst Haeckel a German biologist, naturalist, philosopher, and artist who discovered, described and named thousands of invertebrates. Haeckel was deeply impressed by Darwin's Origin of the Species by Means of Natural Selection and became one of the most vigorous proponents of Darwin's ideas in Germany. As his most prominent legacy to biology he coined many words which are commonly used by biologist today. Most importantly, in his book General Morphology of Organisms, published in 1866, he introduced for the first time the word "ecology" in a broad definition which is still valid today: "ecology is the comprehensive scientific study of interactions among organisms and their environment; environment thereby describes all conditions enabling the existence of a species and can be either biotic or abiotic ...".

Haeckel's work was influential for the acceptance of the theory of evolution in German-speaking countries. His chief interests in evolution and life development culminated in the beautifully illustrated Kunstformen der Natur (Art forms of nature), which includes over 100 detailed illustrations of organisms.

The winner of the Ernst Haeckel Prize is invited to deliver an opening plenary, key-note lecture at the biennial EEF Congress and is also presented with a certificate and medal which is designed in the style of Haeckel's fabulous illustrations. The speakers' travel expenses and accommodation costs are covered by the award, allowing them to attend the Congress.

\section{The Ernst Haeckel Prize awardee 2013: Prof. Dr. Ernst-Detlef Schulze}

Professor Dr. Ernst-Detlef Schulze is the founding director of the Max Planck Institute for Biogeochemistry, who, after his official retirement in 2009, continues his research activities in various fields of ecological sciences and nature protection.

Schulze, born in 1941, studied forestry and biology in Göttingen and at the University of California, Los Angeles. He started his academic career with a professorship in Würzburg and Munich. In 1975 he became full professor at the University of Bayreuth where he also served as Director of the Institute of Terrestrial Ecosystem research (BITÖK). In 1997 he exchanged his professorship at the University of Bayreuth with the directorship at the newly founded MPI for Biogeochemistry in Jena. His scientific career began with 
investigating the linkages between plant functions and the cycling of carbon, water and nitrogen. He subsequently enlarged his scientific fields to the observation of large-scale ecosystems and the significance of biodiversity in the global element cycles. Schulze has made seminal contributions to the identification and quantification of carbon sources and sinks with the aim to better understand the causes of the anthropogenic greenhouse effect.

Currently Professor Schulze is engaged in studying ecophysiological processes in trees, exploring continental transects in Australia and Siberia as well as studying soil processes. Being a forester himself, Ernst-Detlef Schulze feels very strongly about the linkages between nature and species conservation and the economic aspects of forest management.

Over the past decades Ernst-Detlef Schulze received numerous awards and recognitions such as the Bavarian State Medal in Silver (1990), the Max Planck Research Prize (1992), the Bullard fellowship of the Harvard Forest University (1997), the Vernadsky Medal of the European Geosciences Union (2004), the Deutsche Umweltpreis (2008), and the appointment as leading scientist at the Siberian Federal University of Krasnoyarsk connected with a fellowship of the Russian government (2010). The Ernst Haeckel Prize is now rewarding the "senior ecologist" for his contributions to European ecological science.

\section{Students' European Ecology Prize}

During the EEF Congress, the Federation awards the "Students' European Ecology Prize" to honour the best oral contribution presented by a student participant. Abstracts submitted to the Congress by students (as first author and presenter) will be reviewed by a committee of the EEF and a selected number of talks will be evaluated by committee members during the conference. The quality of the submitted extended abstract is very important in determining consideration for the prize.

The prize is endowed with $€ 200$ and a free publication in Web Ecology.

In 2011 the prize was presented to Anne Kempel, University of Bern. In 2013 no awardee was evaluated. 